\title{
PAPÉIS SOCIAIS DE GÊNERO E CONFLITOS NAS DIMENSÕES DE RACA, CLASSE E GERAÇ̃̃O DE MULHERES - MÃES NO MUNICIIPIO DE VITÓRIA DA CONQUISTA-BA
}

\author{
SOCIAL GENDER ROLES AND CONFLICTS IN THE DIMENSIONS OF RACE, CLASS AND GENERATION OF \\ WOMEN - MOTHERS IN THE MUNICIPALITY OF VITÓRIA DA CONQUISTA-BA
}

\section{RESUMO}

Este texto analisa os resultados parciais de uma pesquisa realizada com sete mulheres-mães no município de Vitória da Conquista-BA, no ano de 2017, em que narram suas experiências nas relações intrafamiliares, detidamente com seus filhos e filhas, mas não somente. O objetivo é trazer à tona as percepções relacionais que tais mulheres possuem de si mesmas em torno das identidades maternas e dos papéis conjugais exercidos no âmbito das relações de poder sociofamiliares, bem como compreender alguns conflitos decorrentes das mesmas - repletas de ambiguidades - e as distintas formas de lidar encontradas por elas. A análise é feita a partir de um olhar que intersecta diversos lugares de pertencimento, problematizando distintas localizações de classe, raça, geração, nível de escolaridade, ocupação espacial atual e outros marcadores sociais emergentes na investigação em campo - estruturais ou circunstanciais - como a procedência e origem geográficas, e, assim, desvelar certa pluralidade de experiências e percepções sobre ser mulher-mãe. Para a apreciação e sistematização dos relatos, ancorei-me na análise qualitativa viabilizada através da categorização e análise de conteúdo inspirada em Bardin (1977), além da valoração das subjetividades das falas por meio de estratégias metodológicas com o uso da história oral (MAGALHÃES, 2002).

Palavras-chave: Maternidades. Pluraridades. Mulheres negras. Gênero.

\begin{abstract}
This text analyzes the partial results of a survey carried out with seven womenmothers in the municipality of Vitória da Conquista-BA in 2017, in which they narrate their experiences in intra-family relationships, with their sons and daughters, but not only. The objective is to bring out the relational perceptions that these women have of themselves around maternal identities and conjugal roles exercised within the scope of social-family power relations, as well as to understand some conflicts arising from them - full of ambiguities - and the distinct ways of dealing found by them. The analysis is made from a look that intersects several places of belonging, problematizing various positions different class locations, race, generation, level of
\end{abstract}

Luciana Cristina Teixeira de Souza

Doutora em Estudos de Gênero e Feminismos (PPGNEIM/UFBA, 2020). Professora do Curso de Licenciatura em Geografia da Universidade do Estado da Bahia (UNEB). Membro dos grupos de pesquisa: GAD -NEIM e GEOREDE-UNEB. E-mail: lunasouza83@gmail.com 
education, current spatial occupation and other emerging social markers in field research - structural or circumstantial - as the geographical origin and origin, and, thus, unveiling a certain plurality of experiences and perceptions about being a woman-mother. For the appreciation and systematization of the reports, I anchored myself on the qualitative analysis made possible through the categorization and content analysis inspired by Bardin (1977), in addition to the valuation of the subjectivity of the speeches through methodological strategies with the use of oral history (MAGALHÃES, 2002).

Keywords: Motherhood. Pluralities. Black women. Gender.

\section{Introdução}

Na presente pesquisa, busco compreender e analisar o processo de elaboração que sete mulheres-mães entrevistadas ${ }^{1}$ revelaram, em trechos de suas narrativas, a respeito dos seus lugares sociais desde a condição materna, suas concepções de mulher, esposa, mãe de seus filho/as e das relações daí estabelecidas. A pesquisa de campo foi realizada no município de Vitória da Conquista-BA, ao longo do ano de 2017, com mulheres pertencentes a grupos de idade/gerações entre 42 e 65 anos. Interessa-me trazer à tona as percepções que tais interlocutoras têm de si mesmas em torno das identidades maternas e dos papéis conjugais exercidos no âmbito das relações de poder sociofamiliares estudadas, bem como compreender os conflitos decorrentes dessa relação - repleta de ambiguidades -, e as distintas formas de lidar encontradas por elas.

Para a realização desse estudo foram selecionados, além das fontes bibliográficas e revisão de literatura, recortes de sete entrevistas semiestruturadas com mulheres que vivem em uma mesma cidade - de porte médio, mas com distintas localizações de classe, raça, geração, nível de escolaridade, ocupação espacial atual e outros marcadores sociais emergentes na investigação em campo, estruturais ou circunstanciais, como a procedência /origem geográficas. Para a apreciação e sistematização dos relatos, ancorei-me na análise qualitativa viabilizada através da categorização e análise de conteúdo inspirada em Bardin (1977), além da valoração das subjetividades das falas por meio de estratégias com o uso da história oral. A base empírica foi operacionalizada pela produção dos dados coletados através de instrumento elaborado no formato de um roteiro de perguntas. Vale dizer que faço a opção de chamar as interlocutoras dessa pesquisa por "narradoras" das suas vidas, compreendendo-as como sujeitas sociais, que narram e refletem sobre suas experiências frente ao grupo familiar do qual são parte, sobretudo, porque trata-se de uma pesquisa amparada nas epistemologias feministas, cujos pressupostos, entre outros, constituem o reconhecimento e a visibilidade da autoria feminina.

1 Todas as interlocutoras tiveram seus nomes substituídos de modo a garantir o anonimato e a confidencialidade dos relatos. 
Assim, busquei respeitar o protagonismo das narradoras no exercício de enunciar suas percepções e conflitos vivenciados, na mesma linha do que inspirou a historiadora Nancy Magalhães (2002), quando argumentou sobre narradores serem potenciais pensadores da sua própria realidade porque:

O espaço do direito à fala, do direito à palavra pode, assim, fazer emergir práticas de sujeitos de suas próprias histórias, que também deliberam sobre os seus rumos, seus desejos de completude, segurança, proteção, aventura, como disputas de poder na sociedade, afirmando que esses devem ser direitos abertos e accessíveis a outras pessoas (MAGALHÃES, 2002, p. 68).

Desse modo, complemento o atributo "narradoras" com o apóstrofo "pensadoras", para me reportar as mulheres aqui apresentadas, de maneira a respeitar a forma própria de reflexão das mesmas sobre suas trajetórias e experiências.

Para a pesquisa maior, foram entrevistadas, ao todo, dez mulheres com trajetórias de conflitos intrafamiliares que se dispuseram não só a responder à entrevista, como partilharam suas vidas confiando a mim suas narrativas de dor, mas também de superação e agenciamentos das suas experiências como mulheresmães. Entretanto, como dito, para a análise do presente artigo, selecionei recortes de entrevistas de sete narradoras-pensadoras a fim de dialogar com elas nesse texto, em razão das reflexões que tais narrativas suscitaram para a discussão proposta pelo dossiê, no tocante aos papéis sociais de gênero e de maternidades.

Por fim, confrontei os dados produzidos conjuntamente com a base conceitual de modo a demonstrar e problematizar as teorias apresentadas.

\section{Sentidos de maternidades no feminismo ocidental}

Segundo Lucila Scavone (2001), o debate sobre a maternidade no feminismo hegemônico - protagonizado majoritariamente por mulheres brancas -, sofreu muitos deslocamentos em suas formas de abordagens ao longo do desenvolvimento das discussões internas no movimento feminista, nas ruas e/ou na academia, indissociavelmente. Tais abordagens trilharam por significados e sentidos diversos dados à noção de maternidade ao longo da história. Conforme a autora, em princípio, a crítica feminista sobre a maternidade considerou que esta seria "um elementochave para explicar a dominação de um sexo sobre o outro" (SCAVONE, 2001, p.142). Entretanto, ao longo de décadas, o pensamento acerca da função da maternidade seguiu atualizando a complexidade social da sociedade contemporânea.

Outrossim, com as contribuições mais atuais, a partir dos usos do conceito de gênero para o fenômeno da maternidade, superou-se as teses biologistas prevalentes até final do século passado. Tal marcador apontou para a compreensão relacional da maternidade. Novos elementos passam a ser considerados, a saber: a paternidade; 
paternagens e maternagens; a maternidade como símbolo de idealização e também de opressão ou de poder; a família e suas diversas modalidades; homens que engravidam; o contexto social em que se insere e até mesmo as novas modalidades de contracepção e reprodução artificiais e seus impactos sobre a autonomia e liberdade das mulheres. Os estudos relacionais ampliaram a visão analítica e a crítica de modo mais complexo e renovado, trazendo muitas possibilidades de interpretação sobre a questão. Pois, "este rompimento levou à separação definitiva da sexualidade com a reprodução [...] e desconstruiu a equação mulher=mãe [...]” compulsória (SCAVONE, 2001, p. 142-146).

Desde as discussões sobre as relações sociais de sexo como de gênero, até a consideração das ideias de parentalidades, outras noções estão sendo desenvolvidas e se atualizando para acompanhar a complexidade cada vez maior de um período marcado por transições velozes e significativas no tocante à formação dos rearranjos familiares.

Ainda na década de 1980, a clássica obra produzida pela filósofa francesa Elisabeth Badinter: Um amor conquistado: o mito do amor materno (1985) foi aclamada por grande parte das feministas. Este livro se tornou campeão de vendas na década de 1980, tamanha polêmica trazida nas suas reflexões acerca da construção social do amor de mãe. ${ }^{2}$ A autora realiza importante resgate das transformações na imagem da mulher-mãe, de seu papel e de sua importância no ambiente familiar ao longo dos períodos históricos. Segundo afirma Badinter (1985, p. 145), a sociedade foi submetida às orientações sociais que "[...] impõem à mulher a obrigação de ser mãe [...] e engendram o mito [...] do instinto materno, ou do amor espontâneo de toda mãe pelo filho".

Sob tal perspectiva, criticada por Badinter, o sentimento da maternidade passou a ser concebido como algo natural às mulheres, sendo considerado uma característica universal feminina, indicando que toda mulher deveria experimentála, independente da cultura ou do seu grupo social.

Nesse sentido, o amor de mãe é apresentado como pré-estabelecido, à espera somente do momento em que as mulheres aceitem viver suas tarefas maternas. Entretanto, a autora alerta que esse chamado à maternidade não ocorreu sem questionamentos. Houve muita resistência à adesão desse modelo de sociedade por parte de alguns segmentos de mulheres, porque, segundo ela: "Quando tem ambições (mundanas, intelectuais, ou profissionais [...] e meios para realizá-las) uma mulher é infinitamente menos tentada do que outras a investir seu tempo e sua energia na criação dos filhos" (BADINTER, 1985, p. 228).

Com o apoio dessa leitura, compreende-se que a maternidade é um fenômeno social. Apesar da identidade materna possuir o componente afetivo expresso pela

2 A argumentação de Badinter é a de que, como todos os sentimentos humanos, o amor materno pode ser incerto, frágil e imperfeito. Portanto, sua tese chocou com a ideia de haver um suposto instinto maternal idealizado pelos modelos da "boa mãe" e da "mulher normal" prevalente nos séculos XVIII e XIX na Europa e propalado desde o "discurso médico herdado de Freud". Esses ideais ancoraram as campanhas em favor do aleitamento materno sob argumento da função social da mãe, dada a sua natureza reprodutiva e o destino biológico das mulheres. 
empatia e responsabilidade da mãe em relação ao filho, esses laços são representações históricas e culturalmente definidas por sentimentos associados ao papel materno, vez que não existe uma identidade dada pela natureza. Sendo assim, "atribuir a alguém o papel de filho, implica, ao mesmo tempo, que alguém assume o papel de mãe, pressupondo que ambos se manifestarão de acordo com os respectivos papéis" construídos culturalmente, como aponta Amélia Kimura (1997, p. 340). Com o adendo de que tais expectativas nem sempre serão cumpridas.

A abrangência cultural dos papéis maternos dominantes esperados a se desempenhar socialmente, indica reflexões importantes sobre o silenciamento e a invisibilidade que cercam fenômenos como os da violência intrafamiliar, em especial aqueles ocorridos contra mães em contextos mais gerais. Há de se compreender que sejam temas considerados tabu, um solo intocado, ao serem provocados, discutidos e desvelados nas sociedades cujas tradições seguem cristalizando o papel social da maternidade. Afinal, a expectativa geral da sociedade em relação ao papel exercido/ gerido pela mãe é aquele correspondente ao seu suposto amor materno 'natural', atávico e à sua abnegação diante dos conflitos vivenciados no interior da família a quem lhe caberia o dever de mediar os distintos interesses e preservar a harmonia no grupo familiar.

Sendo os modelos hegemônicos de maternidade ainda culturalmente muito presentes nas sociedades ocidentais - dirigidos às mulheres normativas, casadas e das elites -, talvez esta seja, entre outras, uma razão pela qual os estudos na área indicam que é muito difícil identificar os registros e/ou denúncias oficiais ou nãooficiais da ocorrência de agressões perpetradas por filhos contra mães. Como aquele apontado por Britto da Motta (2009, p. 5) ao se referir à violência intrafamiliar sofrida por mulheres idosas: "O caso das mulheres idosas é frequentemente silenciado ou 'abafado' pela família - ciosa de sua imagem social de proteção e tranquilidade [...]”. Embora em várias momentos das minhas entrevistas, algumas mulheres demonstrem subverter esse lugar pré-estabelecido e cristalizado no modelo de mãe ideal, transgredindo seus papéis fixos e contestando as grades que as aprisionam em lugares sociais pré-definidos. Mas o tema das subnotificações não é o objeto a ser explorado nesse texto.

\section{Contra-narrativas sobre ser mulher-mãe: outras vozes}

Em que pese haver uma supremacia ocidental nas narrativas sobre o ideal de mãe, faz-se necessário demarcar a dimensão racial e espacial das representações maternas. Pesquisas, como a realizada por Lorena Telles (2018), atestam diferenciações importantes na atribuição e expectativa em torno do papel social de mãe entre mulheres brancas e mulheres negras. Segundo a autora, no séc. XIX, em alguns países colonizados no Caribe, assim também no Brasil, a função de cuidar e amamentar os filhos das senhoras brancas escravistas era 
atribuída às mucamas, mulheres africanas escravizadas e suas descendentes, paradoxalmente à já vigente construção do ideal materno elitista europeu desde o sec. XVIII. Reminiscências desse passado/herança colonial foram encontradas em algumas narrativas sobre funções maternas que apresento adiante, o que denota a presença de práticas sociais colonialistas reatualizadas em nossa sociedade até os dias de hoje.

Mesmo não sendo inteiramente contemplados na base empírica desta pesquisa, destaco que temas ligados às subjetividades, à objetificação, à hipersexualização, à solidão da mulher negra (PACHECO, 2013); à violência obstétrica (LEAL, 2017); e à perda materna constante das mulheres-mãe negras, vitimadas pelo genocídio da juventude preta e pobre (ARGOLO, 2018), além do debate sobre maternidade-solo e abandono paterno, são aspectos que marcam outras nuances da experiência das mulheres, reivindicados pelo feminismo negro, que reconhece nessas vivências negras na condição de mulher-mãe, um contraponto às experiências vividas pelas mulheres brancas e pertencentes às classes mais abastadas, como a pauta pela legalização do aborto, só para citar outro exemplo bastante caro e controverso no cenário tão plural das lutas feministas. Para tanto, recorro à relevante análise histórica que faz Angela Davis ao ilustrar a diferenciação das experiências de ser mãe-mulher clivadas por raça, remontando desde o período da escravidão:

A exaltação ideológica da maternidade - tão popular no século XIX- não se estendia às escravas. Na verdade, aos olhos de seus proprietários, elas não eram realmente mães; eram apenas instrumentos que garantiam a ampliação da força de trabalho escrava. Elas eram "reprodutoras" - animais cujo valor monetário podia ser calculado com precisão a partir de sua capacidade de se multiplicar. Uma vez que as escravas eram classificadas como "reprodutoras", e não como "mães", suas crianças poderiam ser vendidas e enviadas para longe, como bezerros separados das vacas. Um ano após a interrupção do tráfico de populações africanas, um tribunal da Carolina do Sul decidiu que as escravas não tinham nenhum direito legal sobre suas filhas e filhos (DAVIS, 2016. p. 25-26).

Essa diferenciação no modelo ideológico sobre a maternidade evidencia, nitidamente, seu padrão racial tendo raízes ainda no período colonial. Contudo, tal padrão se materializa tragicamente no presente, reificando-se através das hierarquias reprodutivas que indicam como algumas maternidades são mais ou menos legitimadas e aceitas socialmente do que outras. Uma expressão dessa diferenciação é a denúncia da violência obstétrica ${ }^{3}$ da qual as mulheres negras são historicamente as principais

3 Para aprofundar essa discussão ver: TELLES, L.F.S. Bacias, fetos e pelvímetros: mulheres escravizadas e violência obstétrica na enfermaria de partos do Rio de Janeiro (década de 1880). In: ARIZA, Marília \& CARULA, Karoline (org.). Mulheres e escravidão: aspectos da maternidade nas Américas (XVIII-XIX). 
vítimas no sistema de saúde do Brasil. Segundo os estudos de Maria do Carmo Leal (2017), a superação das violências nas trajetórias reprodutivas das mulheres negras ainda precisa ser alcançada por meio da justiça reprodutiva, através de políticas públicas que reconheçam as hierarquias e o racismo institucional existentes no serviço de atenção às mulheres.

Mas, infelizmente, as denúncias sobre o status de humanidade da mulher negra não cessam na violência obstétrica. Em suas pesquisas sobre as memórias da colonização, Grada Kilomba (2019) traz imagens que representam, ainda hoje, a estigmatização dos corpos das mulheres negras. Ancas largas, parideiras, quadris largos são distintivos atribuídos aos corpos dessas mulheres, relacionando-os a estereótipos e expectativas de sexualização e reprodução. Portanto, em uma sociedade estratificada por classes, raças, diferentes culturas, religiões e características socioeconômicas, a cada lugar e tempo pode-se definir políticas e ações que terão distintos rebates sobre a experiência das mulheres, conforme acusa, novamente, Angela Davis (2016). Ao analisar o debate, já em outro momento histórico, sobre controle de natalidade no contexto do movimento feminista nos Estados Unidos, ela observa:

Cada vez mais, aceitava-se nos círculos do movimento que as mulheres pobres, tanto negras quanto imigrantes, tinham um "dever moral de restringir o tamanho de sua família". O que era reivindicado como um "direito" para as mulheres privilegiadas veio a ser interpretado como um "dever" para as mulheres pobres (DAVIS, 2016, p. 203).

Muitos outros trabalhos fazem coro com as ideias de Angela Davis, ressaltando o viés de classe e o racismo que marcam tanto as reivindicações da luta feminista hegemônica, como as políticas de controle de natalidade seletivas, sobretudo, em países de população negra e pobre, através de medidas de esterilização em massa e programas de distribuição de contraceptivos por parte dos Governos atuando em parceria com a ambiciosa indústria farmacêutica. Desse modo, percebe-se que são as mulheres negras as mais vulneráveis às violências reprodutivas, atravessando desde o planejamento familiar (esterilização forçada/ coercitiva); o momento do parto destituído da escolha (violência obstétrica); e até mesmo a decisão pelo aborto (criminalização nos serviços de saúde/aborto inseguro), uma vez que, no Brasil, o aborto é realizado em clínicas particulares para quem tem acesso e capacidade financeira de custear, ou seja, é legitimado de modo seletivo, guiado pelo poder do capital financeiro e/ou simbólico e interditado a determinado grupo de mulheres.

Rio de Janeiro: Ed. Universidade Federal Fluminense, no prelo. 


\section{Da mãe ideal à mãe total}

Em seu novo livro lançado no Brasil em 2011: "O Conflito, a mulher e a mãe", a autora francesa Elisabeth Badinter revisa as ideias acerca das ambiguidades desse duplo papel existencial e social do par Mulher-mãe, já discutidas no citado "Um amor conquistado: o mito do amor materno" (1985).

$\mathrm{Na}$ obra mais recente, Badinter revisita e reafirma o aspecto da heterogeneidade e da não universalidade presente no desejo das mulheres ao decidirem ser, ou não, mães. Mas, agora, a autora atualiza sua ampla pesquisa realizada em países europeus onde as taxas de natalidade diminuem a cada ano, voltando maior atenção para compreender, nas décadas atuais, os novos mecanismos que influenciam as escolhas pela maternidade e também pela paternidade, focando no papel social representado pela mãe diante dos novos tempos.

As novas pesquisas realizadas por Badinter revelam que a despeito da diminuição das taxas de fecundidade nos países europeus, a escolha pela geração de filhos entre os casais entrevistados permanece constante. Ao serem questionados sobre os motivos de tal desejo, ela constata que as justificativas dadas pelo casal não foram de ordem objetiva/racional. Ambos desconhecem os motivos que os levam a optar pela pater/maternidade. Em suas respostas aparecem as questões afetivonormativas, a exemplo da assertiva de que "um casal sem filhos parece hoje uma anomalia" (BADINTER, 2011, p. 20). Estas são as razões que mais influenciam suas escolhas, embora, nem sempre sejam explicitadas.

Pesquisas como as de Badinter demonstram o quão notório é que grande parte das sociedades ocidentais mantém, ainda, a valorização do modelo familiar hegemônico, que é heteronormativo. Neste padrão, os sucessores (filhas/filhos) são preferencialmente concebidos de forma natural, ainda que com uma prole reduzida, conforme estatísticas dos países ditos centrais ou em desenvolvimento. Como articula Rosa Monteiro: "A família e a maternidade são instituições das mais fortemente culturalizadas ao longo dos séculos, a ponto de as suas organizações e ideologia parecerem absolutamente naturais. Tão naturais que qualquer outro tipo de modelo da maternidade se afigura como inapropriado e mesmo desviante" (MONTEIRO, 2005, p. 54).

Ainda assim, um dos maiores legados das conquistas feministas foi o direito à autonomia reprodutiva e ao planejamento familiar, possibilitado pelo advento dos meios de contracepção, mesmo que nem todas as mulheres no globo se beneficiem dos recursos disponíveis. Entretanto, enfatizo que outras narrativas - a depender do lugar social ocupado - acerca da experiência social das mulheres, podem ser radicalmente diversas frente à maternidade, ao direito de ser mãe, ao casamento e às formações familiares, como descrevem as feministas negras citadas e outras, tendo como pressuposto de que há uma incomensurável pluralidade na experiência feminina. 
Conquanto tenhamos distintas experiências femininas no cenário da justiça reprodutiva, é fato que - seja de modo coercitivo (mulheres negras) ou voluntário (mulheres brancas) - nos países centrais e semiperiféricos, as políticas públicas de controle de natalidade e/ou de planejamento familiar empreendidas nas últimas décadas alteraram as pirâmides demográficas diminuindo gradativamente a sua base. De acordo como IBGE, o Brasil se insere nesse contexto ${ }^{4}$. Porém, a despeito da redução do número de filhos e da participação no mercado, não houve uma libertação das mulheres da jornada invisível do trabalho doméstico. Pauta, aliás, que segue recorrente nas bandeiras da luta feminista pela equiparação salarial e de condições de trabalho. Pelo contrário, como alerta Badinter, no seu último livro, nas últimas décadas há o perigo de uma nova onda insurgente no mundo ocidental, que anuncia um novo chamado ideológico pelo retorno à maternidade compulsória, ao que nomeia de uma verdadeira "ofensiva naturista". Na visão da autora, tal discurso ecológico seria um dos responsáveis pelo retorno da 'fibra materna', substituindo, agora, o termo 'instinto materno'. Segundo essa ideologia, esse seria o elementochave para explicar o comportamento feminino atual de parte das mulheres. Tal linha de pensamento tem provocado certos deslocamentos observados no âmbito do próprio movimento feminista com o crescimento da vertente do ecofeminismo.

Essa tendência que está em curso, segundo Badinter, apresenta sérias temeridades no tocante ao retorno de uma "suave tirania dos deveres maternos", que tenta consolidar um modelo uniforme de maternidade, composta por discursos maternalista-biologistas que, ao que tudo indica, tem ganhado espaço entre determinado grupo de mulheres mais privilegiadas. Mas, representa, sobretudo, um apelo ao retorno da mulher ao espaço privado sob o risco de ter negligenciada a sua “principal função” no mundo, qual seja: a de ser mãe, de viver, prioritariamente, para criar e cuidar da sua prole.

Discursos de culpabilização e de repulsão às atribuições maternas e paternas delegadas a outrem como babás e creches, ou mesmo a condenação daquelas que se recusam a optar pelo parto cirúrgico ou a amamentação, têm sido deslindados e propalados de forma feroz por ativistas ecofeministas de plantão nas redes sociais e mesmos em espaços de diálogos entre mulheres, que já tive a oportunidade de assistir. Há uma tendência da propagação de novos espaços de sociabilidades entre mulheres-mães, cujo centro dos debates está na maternidade supostamente responsável, porque ancoradas em tais princípios naturistas.

A pesquisa de Badinter (2011) é, portanto, uma denúncia de como as mulheres têm sido permanentemente convocadas a exercerem o papel normativo da maternidade, abrindo mão de sua vida pessoal e profissional para se dedicar cada vez mais aos cuidados com os outros, cuja personificação maior ainda é o/a filho/a, embora essa fila de necessitados de atenção seja mais ampla, estendendo-se ao marido e a outros parentes, como o cuidado dos pais em sua família de origem. O apelo agora se desloca da 'mãe virgem' para a 'mãe total'. A autora conclui alertando que

4 Ver: IBGE, Diretoria de Pesquisas, Coordenação de Trabalho e Rendimento, PNAD 2015. Disponível em: https://biblioteca.ibge.gov.br/visualizacao/livros/liv98887.pdf 
a retomada do modelo "ideal materno choca-se violentamente contra as obrigações cada vez mais exigentes do mundo do trabalho" (BADINTER, 2011, p. 158), o que poderá aprofundar ainda mais as desigualdades de gênero quanto ao acesso a cargos e salários equitativos.

Contudo, apesar dos estudos de Elisabeth Badinter (2011) constituírem uma grande referência para inúmeras pesquisas no campo das maternidades, é imprescindível ressalvar que suas considerações estão circunscritas às localizações sociais, culturais, geográficas, geracionais, de raça e classe, já que sua base empírica é composta de mulheres europeias, brancas, pertencentes a grupos em idade de reprodução biológica e localizadas nos setores da classe média.

Diante das conclusões de Badinter (2011), que analisou sujeitas delimitadas socialmente, mas corroborando com a sua crítica, caberia suscitar outras perguntas a novas e sugestivas investigações: e quanto 'as mulheres negras periféricas, essas também seriam convidadas ao ideal de maternidade ecoado pelo 'novo' movimento naturista do ecofeminismo? Elas fazem parte desse clube de mães de classe média, branco e burguês? Sua condição existencial na qualidade de mãe preta - pré-condicionada socialmente pelas localizações de classe, ocupação espacial, escolaridade, entre outras - as credenciam ao molde ecológico de maternidade que implica abdicar do mundo do trabalho para cuidar dos filhos? Além disso, teriam acesso a serviços de saúde que garantam parto humanizado público, aleitamento materno, alimentação saudável e outras condições pré-requisitadas para esse ideal? Ou seriam essas mulheres, parte de um outro grupo, outro ethos, ocupando a outra margem da estrutura social e que precisam resistir, a todo custo, nessa ordem, conciliando seu papel social de mãe, muitas vezes solo, com a condição de mulheres trabalhadoras para garantir a existência de suas maternidades, mesmo fora do padrão idealizado? Com quais redes, grupos, ou clubes de solidariedade de mulheres ou homens elas contariam?

Considerando que a mensagem social da maternidade ideal alcance todas as mulheres em distintos lugares de raça e classe, o discurso em torno da amamentação e do cuidado acaba afetando ainda mais negativamente as mães que, por várias razões, inclusive biológicas, não conseguem amamentar, tampouco se dedicar integralmente à cria - como manda tal manual. Só que, ao não fazê-lo, elas sentem-se amputadas em sua maternidade. Portanto, estes discursos, cada vez mais fortes e correntes nas redes sociais, podem afetar muitas mães pretas e pobres que também o consomem e idealizam essa maternidade, se cobrando e se sentido culpadas pelo que não podem ser, dada a ausência das condições concretas não asseguradas socialmente.

Feitas as devidas ressalvas na delimitação social do estudo, ainda assim, para a minha pesquisa, as contribuições de Badinter foram de grande auxílio, uma vez que encontrei muita confluência entre as ideias da autora e as narrativas registradas, mesmo tratando de realidades tão distintas daquela pesquisada por ela. Minhas constatações talvez se expliquem pelo fato de que as relações de gênero estabelecidas frente à maternidade e às idealizações em torno da família, seguem, 
em grande medida, experienciadas de forma horizontal pelas mais diversas mulheres do mundo ocidental, tamanha hegemonia do ideal do papel de mulhermãe, ainda que eventualmente algumas práticas de maternidades desobedeçam o modelo dominante e se apresentem de maneira adversa e particular.

Portanto, como disse, identifiquei muitos aspectos discutidos por Badinter na minha pesquisa de campo, sobretudo, no que se refere aos dilemas enfrentados no exercício do papel de mãe mas, também, de esposa pelas mulheres ouvidas. Das sete mulheres selecionadas, seis declararam que se tornaram mães antes dos 30 anos e uma antes mesmo dos 20 anos. Esse dado reflete uma característica marcada pelos costumes e tradição próprios de um contexto socioespacial correlato a uma posição geracional ${ }^{5}$ das sujeitas na condição feminina em idade reprodutiva, ainda que essa não se apresente de maneira uniforme e linear, visto que estão condicionadas a outras diversas clivagens sociais.

Considerando que as narradoras-pensadoras da pesquisa compõem um grupo social que vive numa cidade de porte médio, cuja tradição do casamento e do tornar-se mãe guarda, ainda hoje, traços de ideais conservadores e patriarcais no tocante à formação familiar - como sendo esta a função prioritária e compulsória na vida de toda mulher - e mais, onde ser mãe é o pressuposto de ser esposa, é possível inferir que essas mulheres, situadas atualmente nos grupos de idade entre 42 e 65 anos, sofreram forte apelo sociocultural com o fim de corresponder a tal expectativa e atuação social estabelecidos à sua geração, na época, com a idade reprodutiva idealizada - em torno dos seus vinte anos - para iniciar formação familiar. O relato de Maria Clara, mulher negra de origem pobre, hoje aposentada e que se casou aos 17 anos, é bastante emblemático neste sentido. Segundo afirma:

No primeiro ano até que foi razoável, mas eu não gostava dele, assim, foi uma coisa mais para, sei lá, para poder, eu acho que eu queria ter uma pessoa do meu lado que me controlasse, que me ajudasse, aquela coisa assim paterna, um companheiro... Na época ele tinha, parece que era 28 anos, ele era mais velho do que eu. Os dois filhos foram com ele, aí chegou um ponto que a cachaça predominou assim na vida da gente de um jeito tão grande que eu resolvi sair de dentro de casa, larguei tudo, mas meus filhos, no caso, quando eu saí minha filha já estava com 14 anos, eu aguentei para não deixar nas costas da minha mãe, né, porque afinal de contas os filhos eram meus, a responsabilidade era minha, então eu não queria, que eu nunca gostei que ninguém tá passando nada na minha cara, aí eu me segurei, mas não que eu, na verdade, sabia que ia chegar ao fim, só estava esperando o momento certo e a hora certa. (Maria Clara, 57 anos, 2017).

5 Entendendo posição geracional na perspectiva de Mannheim (1928, p. 152) que diz: "A posição como tal apenas contém as potencialidades que podem ser materializadas, suprimidas, ou incorporadas noutras forças sociais e manifestadas de forma diferente". 
Conforme visto no relato acima, apesar das imposições sociais culturalmente reforçadas pelas tradições do lugar, é interessante analisar a complexidade presente nas respostas individuais de algumas mulheres no tocante à manutenção ou não dessa ordem previamente estabelecida pelo grupo social do qual fazem parte, qual seja: a de se tornar esposa e mãe e, mais importante, de como exercer ambos os papéis esperados. Maria Clara afirma que casou porque "queria" ter uma pessoa ao seu lado e que esperava desse companheiro o papel de pai. A julgar pelos códigos e valores morais que marcaram a sua formação durante a juventude, declarado por ela em algum momento da nossa conversa, é possível questionar se essa decisão foi, de fato, individual, ou se Maria Clara buscava a extensão do modelo da sua própria família ao identificar a função paterna tradicional com a do companheiro, respondendo, assim, à expectativa da transmissão geracional familiar para a qual, certamente, foi influenciada e socializada. No entanto, antes de ficar viúva, ela revelou que desistiu das tentativas de levar o projeto de família adiante em razão dos intensos conflitos vivenciados. Ainda que a dificuldade econômica representasse uma grande barreira a superar para criar os filhos sozinha, essa foi a forma pela qual decidiu contestar e romper com os desígnios socialmente determinados em princípio, para a sua vida, mas, como visto, sem abrir mão de exercer a função materna esperada e, ao que pareceu, também, desejada, recusando-se a transferir tal responsabilidade a outrem. Algumas outras narrativas surgiram nesse sentido, como trago mais adiante.

Vemos o caso de Maria Elvira, mulher negra, periférica, trabalhadora da saúde, que, ao ser questionada sobre a sua convivência familiar, revela que considera tumultuada, porque, segundo ela:

Quando você entra em uma relação que você já vem com filhos, eles, às vezes, sabe que você tem os filhos, mas não aceitam os filhos do jeito que são, sempre tem que criticar. E minha briga com ele a vida toda foi por causa dos meus filhos, porque ele achava que eu não era uma boa mãe, que eu mimava demais, que eu dava muito amor, que eu dava muito carinho que eu dava muita atenção... Então pra ele isso era um defeito (Maria Elvira, 42 anos, 2017).

O relato evidencia um aspecto de como a interlocutora se percebe no papel de esposa e mãe. $\mathrm{O}$ fato do atual companheiro não ser o pai biológico dos filhos, de quem M. Elvira é separada há muitos anos, é considerado um elemento dificultador da sua atual relação conjugal, uma vez que o marido interfere, ou tenta interferir, na forma de criar os filhos, segundo informa. Apoiando-me em Badinter, identifico o paradoxo existente entre a reivindicação das mulheres pelo desejo de partilhar a tarefa de cuidar e criar os filhos com o parceiro e, ao mesmo tempo, não lhes permitir opinar na sua criação. Esse tipo de comportamento pode ser explicado, em grande medida, pela assimilação e cristalização do modelo hegemônico do papel social de mãe, no qual a mulher entende que caberia somente a ela a tarefa de lidar 
com os filhos na sua formação mais direta. O sexismo presente na concepção desse papel maternal é fruto de como homens e mulheres são socializados numa cultura de dominação masculina e, também, de exploração - a divisão sexual do trabalho.

Por outro lado, contraditoriamente, esse aspecto também pode representar vantagens na disputa de afeto e cumplicidade com o filho/filha. Na prática reflete, de acordo com bell Hooks (2019), o aparente paradoxo e, ao mesmo tempo, o agenciamento das mulheres neste processo que pode, inclusive, servir de moeda de troca para 'segurar' um casamento - a depender da relação que o pai tem com o/a filho/a, por exemplo. Um/a filho/a, via de regra, em meio a um processo de separação complica as negociações, porque culturalmente - e isso acaba respingando nas decisões jurídicas, estruturalmente sexistas -, a concepção de que "o filho é da mãe", pode ser mobilizada pela própria mãe em seu favor.

No caso de Maria Elvira, há um elemento atenuante que poderia, talvez, explicar sua interdição na partilha da criação dos filhos com o companheiro atual, seria o fato da não-paternidade biológica do mesmo, considerando-se a manutenção da valorização social dos vínculos consanguíneos, que confere a estes um grau maior de importância na hierarquia das relações familiares. Embora revele não partilhar a mesma casa, M. Elvira assume a relação conjugal como estável e de convivência regular com a família de origem, mas, ao que indica sua fala, tal relação parece não ser suficientemente legitimada ao ponto de considerar a opinião do parceiro nas decisões sobre os filhos.

Vista sob outro ângulo, a não consanguinidade pode representar, para o parceiro, um elemento conflitante e ameaçador dos seus interesses pela atenção e cuidados demandados, o que explica suas reclamações relacionadas à dedicação, carinho e afagos de Maria Elvira aos filhos. Os reclames do parceiro - relatados por ela - se enquadram nas expectativas criadas em relação ao papel que supostamente deveria ser exercido por ela como mulher/esposa, variando desde as chamadas "obrigações matrimoniais" até a execução de tarefas domésticas ou servis dedicadas ao esposo.

Maria Elvira parece ter encontrado uma forma de mediar ou, ao menos, negociar algumas das exigências do parceiro, quando decidiu que iriam morar em casas separadas. Assim, entende que consegue realizar algumas vontades e desejos dos filhos sem a interferência do marido. Em suas palavras:

Quando a gente vivia junto, porque hoje a gente não vive junto, é... eu não podia levar meus parentes na minha casa, meus filhos não podiam levar os amigos deles lá em casa. Eu não podia cortar meu cabelo. Ele mora com a mãe dele e eu moro com a minha. Mas quando morava dentro de casa não tinha isso, não podia isso, não podia aquilo... Eu falei para ela (a psicóloga) que eu estou adorando. Ele não tá gostando não, mas eu estou adorando... não é o que menina?! Viver com uma pessoa 24 h que não tem elogio para te dar. Você ajuda, ajuda e não te elogia em nada. Mas criticar se arranjar uma rodinha de gente para criticar... Às vezes da minha família mesmo (Maria Elvira, 42 anos, 2017). 
Já para Maria Silvia, outra narradora-pensadora desta pesquisa, que é uma mulher branca, escolarizada até o nível superior e professora desempregada, o esforço empreendido ao desempenhar seu papel de mãe e esposa esteve relacionado a todo tempo, enquanto casada, à satisfação e proteção do esposo e dos filhos, respectivamente:

Eu sempre tentava amenizar, esconder... Eu tive assim, um grande problema em relação comigo nesse casamento, porque eu criei um herói para os meus filhos, sabe?! Eu escondia dos meus filhos muitas coisas, para que eles não crescessem com aquilo na cabeça, com aquela ausência, e aí eu... nessa situação foi crescendo ele como o bom, e eu as vezes que... porque mãe reclama muito, né? (Maria Silvia, 57 anos, 2017).

Em outro trecho do seu depoimento, M. Silvia demonstra o quanto abdicou da sua vida acadêmica pra priorizar a contribuição no sustento da casa, os cuidados com os filhos e, como se não bastasse, a formação acadêmica do esposo:

A gente, assim, a vida toda teve uma vida assim padrão baixo e eu trabalhando para ajudar. Aí eu abri mão de duas faculdades para ele fazer as dele. E ele fazendo as faculdades e eu ficando em casa com os meninos. Aí depois, "quando melhorar você volta" e era assim... Por fim, eu terminei minha pedagogia em EAD porque senão eu não terminava, sabe?! Ainda bem que eu consegui (Maria Silvia, 57 anos, 2017).

M. Silvia só conseguiu concluir a faculdade em EAD (Educação a distância) após a separação. Além de abrir mão dos projetos pessoais, ela se sentia no dever de proteção e cuidado da família ao extremo, a ponto de lidar com os problemas familiares sozinha. Compreendia que sua função como mãe e esposa era a de "salvar" a família de toda e qualquer adversidade, ainda que tal esforço lhe custasse alguns adiamentos e abdicações nas escolhas pessoais, como o projeto de se formar, por exemplo. Tal ideia da função materna corresponde às expectativas hegemonicamente presentes, ainda hoje, onde o papel de abnegação e dedicação do amor incondicional aos filhos deve ser central na vida da mulher-mãe. Como identificado por Badinter, a ideia do amor materno se confunde com o mito sobre a maternidade que sacraliza a figura da mãe perfeita, devotada à imagem e semelhança de "Maria, símbolo do indefectível amor-dedicação" (BADINTER, 1985, p. 09).

A atualidade desse ideário social e institucionalmente vigente, é retratada em um filme recentemente ganhador de um dos prêmios do Oscar de cinema, "História de um Casamento" (2019), de Noah Baumbach, que expõe uma cena acachapante, do ponto de vista feminista: a personagem que é a advogada da protagonista treina a sua cliente sobre um suposto manual de comportamento que uma mulher deve 
seguir nos EUA, em pleno século 21. A recomendação é que ela adote estratégias que impressionem positivamente os jurados e o juiz de uma audiência em um processo litigioso de divórcio. Enquanto a personagem principal treina sua fala querendo, de forma espontânea, refletir sobre suas imperfeições e limites como mãe, a advogada a interpela e corrige o relato, afirmando com veemência:

Quando for de verdade jamais diga isso. As pessoas não aceitam a ideia de mães que bebem vinho e gritam com os filhos... Dá pra aceitar a ideia de um pai imperfeito [...]. A ideia de um bom pai só foi inventada há trinta anos atrás [...]. Mas as pessoas absolutamente não aceitam essas imperfeições nas mães. Não aceitam estruturalmente e não aceitam espiritualmente, porque a base de todo esse negócio judaico-cristão é Maria, a mãe de Jesus. E ela é perfeita, e ela é uma virgem que deu à luz, e apoia o filho incondicionalmente, e segura o cadáver do filho depois que ele morre. E o pai não está lá, ele nem trepou com ela. (Fala da personagem 'Nora' a advogada, interpretada por Laura Dern, 2019 e transcrita por mim).

Essa fala remete ao debate sobre a construção social do papel da mãe e a idealização da maternidade, como já discutido. Mas, a este, acrescento um aspecto referente ao pacto e permanência do contrato sexual (PATEMAN, 1993) que estrutura as relações conjugais antes mesmo das relações familiares, priorizando o marido como o agente detentor do direito sexual, antes de valer-se de seu poder de pai, insistentemente presente nas sociedades ditas modernas.

Encontrei na história relatada por outra narradora-pensadora, Maria Mariá, mulher negra e aposentada deficiente, indícios da manutenção desse contrato que visivelmente pretendeu ser assegurado não somente pelas investidas violentas do pai de seus filhos como marido, demarcando seu lugar de poder durante a vida conjugal, mas, também, pela via do papel repressor da sexualidade da mulher-mãe, assumido por uma de suas filhas em cooperação simbólica com o pai. Ocorre que Maria Mariá decidiu confidenciar uma experiência extraconjugal à sua filha, mas a partir disso, a mesma passou a destratá-la e hostilizá-la. A narradora atribui a este fato, todos os conflitos vivenciados com a filha desde então. Mesmo hesitante, Maria Mariá relatou: "É assim...Não sei, por causa que no passado... Aí, porque... Vou falar a verdade. Eu não gosto de mentira. No passado eu procurei um homem e falava as coisas com ele tudo, e ela sabia disso. É que ela nunca aceitou” (Maria Mariá, 59 anos, 2017). M. Mariá logo identificou a reprovação da filha à sua conduta, ainda que existisse $a$ priori alguma relação de amizade e cumplicidade entre ambas, ao ponto da mãe lhe confiar o segredo íntimo. A relação da filha com o pai, por sua vez, passou a ser cada vez mais estreita. Maria Mariá comenta, ainda, que ambos têm boa relação: "Ah, tem. Maravilhosa. É uma coisa com ele. Eu falei: vou embora e ela: meu Deus.... Você sair daqui? Ela diz: mas, meu pai é bom demais pra mim”. Aí eu falei: então fica com ele" (Maria Mariá, 59 anos, 2017). Ao se manifestar de maneira rude e intolerante frente 
à opção feita pela mãe quando esta decidiu dar vazão à sua sexualidade em um dado momento da vida, com o agravante de não ser o patriarca da família, exclusivamente, o escolhido para tal, a filha dessa narradora incorpora o papel de vigília e controle patriarcal sobre o corpo da mãe.

Esse comportamento revela uma das facetas da ordem patriarcal de gênero da família que opera no sentido de disciplinarização da mulher, do seu corpo, da sua sexualidade e da sua vida como um todo. O fato da mãe ter "saído da linha", aos olhos da filha, foi motivo de sua reprovação e punição com o tratamento sutilmente agressivo e indiretamente acusatório investido contra a mãe, a submetendo à constante violência simbólica - a partir do fato anunciado, segundo percebeu e refletiu M. Mariá.

Em pleno século 21, após a luta pela liberdade sexual e pelo direito ao autoconhecimento do prazer feminino como símbolo identitário forjados na revolução feminista em voga, diversas forças e diversas frentes (família e outras instituições) ainda operam na vigília incessante sobre o comportamento sexual das mães e sua consequente condenação moral, porque a elas não caberia, supostamente, o direito 'transgressor' ao prazer. Mas, graças às 'deusas' feministas da libertação sexual e/ou a decisões individuais, muitas de nós, mulheres, aprendemos a desobedecer.

No caso de Maria Mariá a desobediência lhe rendeu a animosidade com a qual a filha vigilante passou a tratá-la. Porém, não fosse o seu ímpeto de transgredir, por um momento, a sua identidade de 'esposa' e mãe dedicada, ela não teria, minimamente, retomado o prazer dos sentidos em outras esferas alheias ao doméstico. Ao romper com seu estado de 'mãe virgem' e talvez de 'mãe total', ela passou a exercer o direito à sua sexualidade escolhendo com quem, como e quando decidiu fazê-lo. Maria Mariá, hoje, segue a vida morando sozinha e dona de todas as suas decisões.

Por outro lado, ainda que muitas rebeldias gritem fora das grades sociais dos papéis cristalizados de gênero, existe muito trabalho feminista a ser feito a fim de romper pública e estruturalmente com o modelo universal do receituário sobre o comportamento feminino, sobretudo, se a mulher for mãe. Amiatta Forna (1999) corrobora com a análise e resume a concepção sobre o papel idealizado da mulhermãe como prevalente em muitos grupos familiares até os dias atuais. Como visto no caso de Maria Silvia e de outras interlocutoras, a maternidade implica, ainda em grande medida, em: "Ser completamente devotada não só aos filhos, mas a seu papel de mãe. Deve ser a mãe que compreende os filhos, que dá amor total e o mais importante, que se entrega totalmente. Devendo ser capaz de enormes sacrifícios" (FORNA, 1999, p. 11).

Para Badinter (2011), a mulher que permanece executando incontáveis e repetidas atividades, dedicando tempo integral ao seu papel de mãe no âmbito privado, costuma responder que "não faz nada" quando indagada sobre sua situação ocupacional. Dessa maneira confunde "trabalho" com "emprego". Foi exatamente o que Maria Silvia respondeu, de pronto, ao ser questionada sobre a sua atual ocupação, uma vez que está desempregada, mas segue executando as tarefas de casa sozinha. Esta autopercepção sobre “ser mãe” também remete ao termo 'maternagem' 
cunhado por Nancy Chodorow (1978 / 1990/ 2 ed.) para se referir à dimensão social da maternidade, isto é, aos cuidados com os filhos, cuja responsabilidade social caberia à mãe, genitora ou não. Sob essa ótica, a interlocutora exercia a sua maternagem concebendo-a como intrínseca e compulsoriamente definida.

\section{“Adoção à brasileira” - outra forma de ser mãe?}

Ainda sobre a percepção do papel social materno e conjugal, encontrei no relato insólito (dada a complexidade da condição) de Maria Nádia, uma mulher branca, escolarizada e servidora aposentada, a forma bastante peculiar como ela percebe ter conduzido e exercido a sua suposta função maternal ao lidar com uma jovem não concebida por ela mas, também, não adotada na forma legal prevista nos parâmetros do Estatuto da Criança e do Adolescente - ECA, que regulamenta a adoção no país. Seu relato fornece informações que vão demonstrar a grande complexidade da sua experiência como mãe no bojo de intensos conflitos domésticos que viveu Maria Nádia, como se pode notar no trecho a seguir:

Aí que eu me mudei para minha casa, veio a primeira preocupação: quem vai cuidar do meu filho pra eu trabalhar? Eu já estava trabalhando na justiça, eu já era funcionária da justiça há dois anos e pouco lá... Então quando eu me mudo lá para casa, então era um lugar onde eu não conhecia vizinho, eu não tinha contato com praticamente ninguém, bairro novo. Na minha convivência, não tinha contatos lá, aí precisei realmente contratar alguém pra cuidar do meu filho, né?! Aí vem aquele cuidado “- e quem vai ser essa pessoa?"; a preocupação por ser, assim, uma pessoa responsável, cuidadosa, com todos os cuidados. Aí eu fui falar com minha irmã pra me dá um suporte. Eu trabalhava o dia todo, eram dois turnos nessa época. Aí ela falou que ela não podia ir, mas que ela poderia ceder uma sobrinha nossa que morava com ela, que ela criou inclusive, aí começamos... Aí precisaria de uma autorização dos pais da menina. Nós teríamos que ir na fazenda, que eles moravam na fazenda, moram até hoje, irmã mais velha pedir autorização a eles para que a menina viesse morar com a gente, né?! Aí fizemos isso, com a autorização da minha irmã que mora aqui, que tinha criado minha sobrinha, e fomos atéa fazenda, pegamos a autorização, a menina veio morar com a gente e tal, tudo bem?! Então nós não tínhamos um documento de guarda, mas informalmente assumimos a responsabilidade sobre ela. Aí ela veio trabalhar comigo, morar comigo e a minha condição ali já era de mãe, não mais de tia e sobrinha, mas de mãe e filha. Então, mesmo ela cuidando de mim, do meu filho, eu cuidava das outras coisas, ela cuidava do meu filho e ajudava em alguma coisa dentro de casa (Maria Nádia, 52 anos, 2017 grifos meus). 
Sua narrativa é a fratura exposta de uma prática 'familiar' comum, legitimada, mas ilegal e historicamente realizada no Brasil, tanto que já se convencionou chamála no meio jurídico de "adoção à brasileira" (ROCHA, 2010). Sobre a questão, Jane Queiroz (2002) argumenta melhor dizendo que:

\begin{abstract}
Há nessa relação uma intenção subjetiva, envolta camufladamente no desejo de garantir mão de obra doméstica, companhia e cuidados aos idosos e membros da família adotante. Essas crianças frequentemente são do sexo feminino, vivem em condições de trabalho escravo, muitas vezes caladas pela violência doméstica e até abusadas sexualmente por membros da família. Esse é um procedimento antigo, tem raízes culturais na própria colonização, porém, não perdeu sua prática nos dias atuais (QUEIROZ, 2002 p. 2).
\end{abstract}

Como visto na afirmativa, as consequências dessa prática, corriqueira em sociedades de herança colonial, como no Brasil, são muito trágicas socialmente, sobretudo, considerando o custo pessoal, cognitivo, psicológico e emocional para a maioria das crianças e adolescentes vitimada. Todavia, para Maria Nádia, essa decisão também deixou marcas bastante profundas com sérias reverberações nas relações familiares, uma vez que seu companheiro, de fato e lamentavelmente, estuprou e engravidou a suposta filha adotiva. Mas, o que trago para a discussão, neste momento da pesquisa, é sobre a sua percepção da maternidade em relação à adolescente trazida do interior para cuidar dos filhos biológicos gerados por ela.

Ao afirmar que estabelecia uma relação maternal com a sobrinha, Maria Nádia desconsidera, deliberadamente, a condição de trabalho infantil à qual a família submeteu a adolescente durante o tempo de convivência comum na mesma casa. Sua função, acertada previamente, era a de ser a cuidadora dos filhos pequenos e ainda “cuidar de alguma coisa dentro de casa”, sem perceber remuneração alguma para tanto. No relato é possível notar que a sobrinha já teria exercido função anterior de servir a outra parte da família, tendo sido "cedida" da casa da irmã da interlocutora; o que agrava ainda mais a condição de repetida exploração sofrida dentro de uma parte da própria família, que hierarquicamente é mais privilegiada do que aquela de origem da mesma. M. Nádia vive com sua família no centro urbano e certamente é detentora de mais posses, marcando a posição de classe média ocupada por ela, sendo, ainda, uma mulher branca, escolarizada e servidora pública, portanto, relativamente privilegiada.

Chama a atenção, também, o fato da interlocutora ter sido funcionária da justiça, ao que se supõe o acesso e a obediência aos parâmetros legais. Mas, diante dos privilégios e benefícios recebidos, isso pareceu não ser relevante para aquela escolha do tipo informal de adoção. $O$ fato explica a naturalização com que se reproduz e se reifica o costume na nossa sociedade, tanto mais sob os auspícios de uma suposta ação de boa fé e generosidade maternal, conforme declarou. Como visto, essa prática arraigada pela herança colonial servil mostra uma outra faceta do papel 
social da maternidade exercido em muitas famílias brasileiras, constituindo-se como característica bastante peculiar no Brasil, ao ponto de receber a alcunha de "adoção à brasileira" no campo do Direito. A relação expressa hierarquias de poder forjadas não pela diferenciação de gênero, mas de outros pertencimentos que entram em jogo, comumente de raça, de classe e posição geográfica privilegiada ocupada no espaço urbano, uma vez que um dos principais argumentos utilizados para tal rearranjo seria o acesso à escola e a outros bens e serviços supostamente alcançados por parte das crianças e adolescentes que costumam sair de lugares distantes dos centros, da zona rural, periférica ou cidades menores. Infelizmente, em muitos casos, nem sempre o acesso à escola é garantido.

Não obstante, na trama interseccional dos lugares sociais atuantes na questão da "adoção à brasileira", observa-se, também, a evidente dimensão geracional, visto que o alvo preferencial dos sujeitos que perpetram tal prática são crianças e adolescentes. Em razão dos grupos de idade aos quais pertencem, sendo tutelados por seus responsáveis legais, inúmeros jovens e crianças se encontram vulneráveis à decisão tomada pelo interesse dos adultos para benefício próprio, em detrimento do bem estar e da integridade física, psicológica e emocional dos primeiros. Como bem lembrou Saffioti (2001, p. 134): “Ocorre que a sociedade não é apenas androcêntrica, mas também adultocêntrica”.

Nesse jogo de poder e favorecimento mútuo em prol do universo adulto, tanto dos pais biológicos como dos pais adotivos - cada qual ao seu modo -, o custo social estratosférico dessa prática corriqueira e naturalizada numa sociedade de mentalidade colonial como a nossa, é a flagrante licença da manutenção da exploração do trabalho infantil, sob a desfaçatez da oferta e do cumprimento do papel social da maternidade e mesmo da paternidade e, em última instância, do abrigo de uma família. No que se refere à relação de Maria Nádia com seus filhos biológicos, ela relatou que eles foram socializados sem a exigência rigorosa do cumprimento de qualquer trabalho doméstico, sob o pretexto de estudarem. Diferentemente de como foi pactuada a relação, supostamente materna, com a filha adotiva, mediante troca de favores domésticos como condição para coabitar e conviver na mesma família. O que leva a crer que a "filha" não porta o mesmo status social dos filhos biológicos, a despeito da forma como fez parecer Maria Nádia em sua narrativa; além do fato de ser a única 'filha' mulher, portanto, esse é outro aspecto que pode explicar a naturalização da atribuição das tarefas domésticas à mesma, dada a sua condição de gênero na divisão sexual do trabalho.

Conforme observa Sueli Gomes Costa (2002), após a Emenda Constitucional no 72, que regulamenta a situação e os direitos trabalhistas das empregadas domésticas - conhecida como a PEC das domésticas ${ }^{6}$ : "a valorização do trabalho doméstico leva à expressiva substituição de mulheres por meninas. Tal fato desvenda mecanismos de redução de preços do salário do emprego doméstico" (2002, p. 307). No caso da narradora M. Nádia, a compensação viria em forma de favores. A autora constata, ainda:

6 Emenda Constitucional no 72, de 2 de abril de 2013 na gestão da presidenta Dilma Rousseff. 
Mulheres mais e menos abastadas vincularam-se a milhares de mulheres mais e menos pobres aplicadas ao trato de suas casas, através de infindáveis tarefas e de um grande número de compensações recíprocas. A saída para estudar, trabalhar e equiparar-se aos homens, ou para a mera permanência no ócio, através da maternidade transferida de umas para outras mulheres, marca seguidos pactos (e guerras) domésticas (COSTA, 2002, p. 308)

Essa relação evidencia o componente de classe no conflito de interesse intragênero, dado pelo papel sexual do trabalho doméstico atribuído historicamente às mulheres, sobretudo, no cuidado dos filhos. Há casos em que este trabalho é transferido, mas quase sempre para outra mulher. Neste sentido, a divisão de tarefas entre si e o par masculino da casa sequer é pensada, reiterando os papéis sociais de gênero.

Na pesquisa de campo, encontrei, também, outro exemplo de reorganização familiar fruto do mesmo fenômeno. Porém, distintamente de como ocorreu com Maria Nádia, a outra interlocutora revelou ter, em sua trajetória, experiência similar vivenciada na sua família, mas, dessa vez, com papéis contrários e reposicionados. É o caso de Maria Cristina que, sendo uma mulher negra, moradora de bairro periférico, hoje aposentada, relata ter autorizado, após anuência do pai, uma das suas filhas a ir morar na capital do estado em casa de uma prima "bacana", sob o pretexto de que ela contaria com a oportunidade de estudar:

Tenho uma prima que é muito assim, bacana e tudo, né? Aí perguntou se eu deixaria ela estudar lá, conseguiu em um colégio uma bolsa integral e tal, tal. Aí eu falei que eu deixaria sim, que eu não ia cortar a sorte dela, né? Aí eu falei: só depende d'eu falar com meu esposo. Aí, como V. tava viajando na época, por sorte, V. ligou no mesmo dia, né? Aí eu falei pra ele do caso: "- Olhe, S. está assim, assim, e assim”. As meninas já estão com colégio. E ela já tinha até começado a estudar. Aí ele falou: “- não, pode mandar, não vamos ser nós a cortar a sorte dela. Providenciei na mesma semana, ajeitei tudo e mandei ela ir. Ta lá até hoje. Tem 17 anos que ela mora lá. Ela lá, no início falava comigo, ligava pra mim e tudo. Depois foi esfriando, sabe? Esfriando, foi esfriando. E eu sou muito assim... Eu não sou de cobrar não das pessoas, ficar falando “- ah, porque você nunca mais ligou pra mim?” Eu falei “- alguma coisa está acontecendo". Essa irmã minha não suportava essa menina, hoje é assim, ó, as duas. Minha sobrinha, que é a filha dela, não suportava ela, hoje é assim. São comadres hoje. Eu não sei o que foi, depois de que foi pra lá.. (Maria Cristina, 6o anos, 2017). 
Interessante notar o ponto de vista de Maria Cristina sobre a decisão tomada para o destino da filha. Essa mulher-mãe vê como "sorte" e uma "oportunidade" para a filha ir morar na casa de uma prima na capital. O que é compreensível se considerarmos o lugar que essa mulher ocupa na hierarquia de classe, raça e procedência espacial. M. Cristina expressa a experiência de maternidade vivida pela maioria das famílias negras que habita os bairros periféricos, cujo acesso à escola, ao trabalho e aos bens e serviços é muito mais dificultado quando comparado às famílias de classe média, como a que pertence Maria Nádia, por exemplo. Portanto, a percepção de cumprimento da maternidade para M. Cristina, está ligada à garantia da melhor condição possível de oportunidades para a filha, ainda que isso lhe custasse o ônus da sua mudança de cidade. Essa percepção, em princípio, seria positivada pelas motivações pragmáticas e objetivas, dada a condição da carência socioeconômica enfrentada pela família naquele momento, não fossem os aspectos subjetivos que entraram em cena com decorrências futuras e que marcaram profundamente sua relação familiar.

Neste sentido, a narrativa de Maria Cristina desvela a outra faceta do impacto familiar fruto da decisão tomada, na medida em que aponta o prejuízo sócio-afetivo como uma consequência do afastamento da filha, que praticamente deixou de manter contato constante com a sua família de origem. E, quando mantém, é permeado por conflitos e desentendimentos. Porém, ao final do relato, mesmo reconhecendo que a sua relação mudou após a saída da filha para a capital do estado, M. Cristina atribui os conflitos existentes entre ambas, à relação dela (M. Cristina) com a sua irmã pertencente à mesma geração (mas de ordem conflitante) - e entre a filha e a sua prima - ambas da mesma geração (e de ordem de aliança). Além da relação de aliança e cumplicidade firmada, também, entre a tia e a sobrinha (relação intergeracional), em detrimento dela própria.

Mas, consideradas todas as contingências que envolveram a experiência materna de M. Cristina, tal argumento pode ser interpretado como 'cortina de fumaça' para tentar justificar o distanciamento afetivo estabelecido entre a interlocutora e sua filha. Ambas enredadas, portanto, pela teia de acontecimentos desenhados por um cenário de carência social e falta de acesso aos direitos mais básicos que acabam por definir socialmente os destinos das relações familiares, especialmente no tocante à relação materna, alargando distâncias e destituindo laços e cumplicidades, em nome de vislumbrar alguma perspectiva de inserção social, por parte de sua mãe, para uma de suas filhas, ainda que muito longe de casa.

Há, no universo das mulheres entrevistadas, um outro caso de adoção afetiva marcada por ambiguidades, ao que vou chamar de 'voluntário-compulsória', dada pela força dos costumes ligada à tal prática em grupos familiares desprivilegiados em muitas sociedades. Trata-se do caso de Maria do Socorro, a mais velha das mulheres da pesquisa, tem 65 anos, é branca e tira seu sustento da aposentadoria e de um pequeno comércio próprio na cidade. Essa mulher possui a guarda legal da neta de 12 anos, desde que sua filha mais velha, mãe da criança, a deixou sob seus cuidados totais. Segundo Maria do Socorro, ela passou a cuidar da neta quando a mãe "pariu, 
abandonou aqui e largou, não vinha nem alimentar, só aparece de vez em quando." (Maria do Socorro, 65 anos, 2017). Por outro lado, a narrativa de M. do Socorro é repleta de referências afetivas à neta, atribuindo, portanto, um grau de importância e centralidade na atenção que ela parece dedicar a mesma, ainda que a neta tenha sido deixada em sua casa e seus cuidados tenham se tornado compulsórios, a despeito da falta destes por parte da mãe biológica:

\begin{abstract}
Aí quando eu cheguei em casa eu chamei a neta, sentei com ela na cama e perguntei: “- oh, vó, porque você mentiu para vovó? Você almoçou onde?" Aí ela falou: “- vovó eu não almocei não, comi pipoca na exposição, porque minha mãe disse que eu falasse para você que eu almocei." Quer dizer, passou um dia comendo pipoca, uma criança com 7 anos de idade (M.do Socorro, 65 anos, 2017).
\end{abstract}

A história dessa narradora se encaixa nas estatísticas dos inúmeros arranjos familiares em que o cuidado é deslocado da figura materna para a figura da avó, a qual cumpre o papel social da maternidade.

Em nossa sociedade esse costume é bastante corriqueiro e pode ocorrer por diversas razões, especialmente nos estratos da classe trabalhadora. Mas, além das contingências de classe e necessidade de auxílio nos cuidados para trabalhar fora, muitas mães costumam solicitar o amparo de suas próprias mães no caso de abandono paterno ou, ainda, por deliberada transferência de responsabilidade sob o pacto do trabalho do cuidado compulsório feminino (HIRATA, 2012) dado por transmissão geracional. Porquanto, a família também constitui um território de solidariedades, compulsórias ou não, como identificou Cecilia Sardenberg (1998). Segundo a autora, as estatísticas mostram que esse arranjo doméstico-familiar chefiado por mulheres é o tipo predominante na sociedade brasileira e na Bahia (GOLDANI, 1994; CASTRO, 1989 apud SARDENBERG, 1998; MACÊDO, 20o8). Tal arranjo também se assemelha àquele descrito por Alda Motta (1998) que, ao estudar a família do idoso, identificou o seu papel de reprodução social da família, cuja diferenciação de gênero e geração define o sustento desta por meio das pensões percebidas pelas mulheres mais velhas.

\title{
Considerações finais
}

Como visto nas análises, as interlocutoras dessa pesquisa pertencem a variadas gerações, origem de classe, raça, e nível de escolaridade. Portanto, diante dessa primeira observação ao chegar em campo, não houve como escapar de uma análise entrecruzada e relacional de tais categorias fundantes que se articulam na produção da experiência individual e/ou coletiva das mulheres. Em vista dessas diferenciações previamente observadas entre as mulheres, procurei capturar as nuances de como cada mulher, como sujeito social, constitui a percepção de si na condição de mãe no seu universo familiar, de acordo com 
suas experiências individuais e também sociais que as atravessaram a partir das posicionalidades ocupadas, suas vivências e subjetivações. Assim, com o propósito de não universalizar as experiências das mulheres foi importante ter, como pressuposto, que as vivências femininas são diversas e que, além dos marcadores sociais impressos nas suas identidades, também podem variar por conta de diferentes estruturas de famílias, de relações de parentalidades, das negociações que cada uma faz, da cooperação e das redes de solidariedades, mas, ainda, pelas contingências de situações de conflitos e trajetórias de violência e opressão. Daí a necessidade de lançar mão de instrumentos e produção de dados que dessem conta de análises para além dos aspectos objetivos revelados.

Desse modo, conforme apreciado, em que pese as construções sociais cristalizadas em torno do significado de amor materno como instintivo e natural ainda serem reificadas pela engrenagem da ordem hegemônica na definição dos papéis sociais, constata-se que não existe uma forma ideal de ser mãe-mulher. $\mathrm{Na}$ tessitura do real-concreto, as relações maternais vão se forjando conforme condições objetivas e subjetivas dadas e/ou produzidas pelas mulheres na sua experiência relacional como sujeitas sociais e de acordo com seus lugares de pertença, suas ações, reações, deslocamentos, e/ou mesmo reiteramentos de papéis sociais pré-estabelecidos.

Os relatos são reveladores de estratégias diversas criadas e geridas por grande parte das narradoras dessa pesquisa em sua vivência como mulher-mãe e mostram certa porosidade nas formas de reação de cada mulher, ao menos de determinados grupos, que se altera conforme o lugar social ocupado, o qual irá influenciar suas ações por meio, também, de muitas outras variáveis do tipo: acesso à informação, à escolaridade, aos serviços sociais e/ou jurídicos, a redes de sociabilidades diversas, se gozam de saúde (física e mental), se possuem autonomia de circulação (não estar em situação de cárcere), entre outras.

Fato é que as mulheres sempre reagem. Ainda que de maneira sutil, gradual e não estruturalmente transformadora da sua realidade imediata, elas se deslocam ao se perceberem como pessoas que não deveriam estar no lugar de sofrimento contínuo. Confrontam seus pares e seus filhos/as, contestam abusos, ou mesmo fogem a fim de se salvar das grades sociais pré-estabelecidas.

No momento em que decidem romper com aquele lugar do papel social historicamente definido ao gênero feminino, há uma quebra do contrato social; tanto mais ao estigma da mulher-mãe que, em princípio, as confinaria no lugar sacralizado de quem a tudo teria que tolerar em nome do seu "instinto ou da fibra materna".

Quiçá a reflexão sobre as experiências das narradoras-pensadoras trazidas aqui, possa fomentar desconstruções idealizadas e congeladas de modelos de maternidades, de modo a contribuir ou vislumbrar estabelecer relações mais respeitosas, humanizadas, plurais, dialógicas, afetivas e prenhes de cumplicidades construídas nas relações parentais. 


\section{Referências}

ARGOLO, Maria Marta Pinto. Construções e deslocamentos nas relações de gênero das mulheres/mães negras vitimadas pela violência policial contra jovens e adolescentes. 2018. Dissertação (Mestrado em Estudos Interdisciplinares sobre Mulheres, Gênero e Feminismo) - Faculdade de Filosofia e Ciências Humanas, Universidade Federal da Bahia, Salvador, 2018.

BADINTER, Elisabeth. Um amor conquistado: o mito do amor materno. Tradução de Waltensir Dutra. Rio de Janeiro: Nova Fronteira, 1985.

BADINTER, Elisabeth. O conflito: a mulher e a mãe. Rio de Janeiro: Record, 2011.

BARDIN, Laurence. Análise de conteúdo. Lisboa: Edições 70, 1977.

BRITTO DA MOTTA, Alda. Violência contra as mulheres idosas - questão feminista ou questão de gênero? Trabalho apresentado ao Congresso da LASA (Associação de Estudos Latino-Americanos). Rio de Janeiro, jun. 2009.

. Dossiê Gênero, família e fases do ciclo de vida. Caderno CRH, Salvador, n. 29, jul.,-dez., 1998. p. 71.

CHODOROW, Nancy. Psicanálise da maternidade - uma crítica a Freud a partir da mulher. Rio de Janeiro: Rosa dos Tempos, 1990.

COSTA, Suely Gomes. Proteção social, maternidade transferida e lutas pela saúde reprodutiva. Estudos Feministas, Florianópolis, v. 10, n. 2, p. 301-323, julho de 2002.

DAVIS, Angela. Mulheres, raça e classe. Tradução de Heci Regina Candiani. São Paulo: Boitempo, 2016.

FORNA, Amiatta. Mãe de todos os mitos: como a sociedade modela e reprime as mães. Rio de Janeiro: Ediouro, 1999.

HIRATA, Helena e GUIMARÃES, Nadya Araujo (Org.). Cuidado e Cuidadoras - As Várias Faces do Trabalho do Care. São Paulo, Editora Atlas S.A., 2012.

HISTÓRIA de um Casamento. Direção: Noah Baumbach, país: EUA, 2019. Duração: 2hı6 min. Disponível na plataforma Netflix.

HOOKS, Bell. O feminismo é para todo mundo: políticas arrebatadoras $4^{\underline{a}}$ ed. Rio de Janeiro: Rosa dos Tempos, 2019. 
KILOMBA, Grada. Memórias da plantação: episódios de racismo cotidiano. Rio de Janeiro: Editora Cobogó, 2019.

KIMURA, Amiatta. F. A construção da personagem mãe: considerações teóricas sobre identidade e papel materno. Revista. Esc. Enf. USP, São Paulo, v. 31, n. 2, p.339-43, ago, 1997.

LEAL, Maria do Carmo et al. A cor da dor: iniquidades raciais na atenção pré-natal e ao parto no Brasil. Cad. Saúde Pública, Rio de Janeiro, v. 33, supl. 1, 2017.

MACÊDO, Márcia dos Santos. Na trama das interseccionalidades: mulheres chefes de família em Salvador. Salvador, 20o8. Tese (Doutorado em Ciências Sociais) - Faculdade de Filosofia e Ciências Humanas, Universidade Federal da Bahia, Salvador, 2008.

MANNHEIM, Karl. O problema das gerações. Sociologia do Conhecimento, Porto, PT. p. $115-176,1928$.

MAGALHÃES, Nancy Alessio. Narradores: vozes e poderes de pensadores. História Oral, n. 5, São Paulo, 2002.

MONTEIRO, Rosa. O que dizem as mães: mulheres trabalhadoras e suas experiências. Coimbra: Quarteto, 2005 p. 54.

PACHECO, Ana Cláudia Lemos. Mulher negra: afetividade e solidão. Salvador: EDUFBA, 2013.

PATEMAN, Carole. Fazendo Contratos, Confusões patriarcais. PATEMAN, Carole. $O$ Contrato sexual. Rio de Janeiro. Paz e Terra. 1993, p.15-65.

QUEIROZ, Jane Bernardes da Silva Franco de. Adoção de má fé e trabalho escravo: Abandono por esperança, adoção de má fé e trabalho escravo na relação familiar com filhos de criação. Artigo científico, Goiânia, 2012. Disponível em: https://pt.scribd. com/document/130260932/ADOCAO-DE-MA-FE-E-TRABALHO-ESCRAVO-1. Acesso em 21 de out 2020.

ROCHA, Antonia Torres. Adoção à brasileira: Aspectos Relevantes. Artigo Científico. Rio de Janeiro, 2010. Disponível em: https://www.emerj.tjrj.jus.br/paginas/trabalhos conclusao/1semestre2010/trabalhos_12010/antoniarocha.pdfAcesso em: 25 ago. 2019.

SAFFIOTI, Heleieth. Contribuições feministas para o estudo da violência de gênero. Cadernos Pagu, Campinas, n.16, p. 115-136, 2001. 
SARDENBERG, Cecilia M. B. Mães e filhas: etapas do ciclo de vida, trabalho e família entre o antigo operariado baiano. Cadernos CRH, Salvador, n.29, p. 21 -47.jul. /dez. 1998.

SCAVONE, Lucila. A maternidade e o feminismo: diálogo com as ciências sociais. Cadernos Pagu, Campinas, n.16, p. 137-150, 2001.

TELLES, Lorena Féres da Silva. Teresa Benguela e Felipa Crioula estavam grávidas: maternidadee escravidão no Rio de Janeiro (século XIX). Tese (Doutorado) - Faculdade de Filosofia, Letras e Ciências Humanas. Universidade de São Paulo (USP). São Paulo, 2018.

Recebido em 21/03/2021.

Aceito em 21/06/2021. 